\title{
The UK Council for Computing Development
}

\author{
Julian L. Bogod
}

\section{The role of computers in developing countries}

Over ten years ago major studies were carried out by the United Nations into the role of computing in developing countries. Two reports were published, in 1970 and 1972, which analysed the then current state of development and identified the close relationship between computing capability and positive development. In 1978 a conference entitled 'Intergovernmental Conference on Strategies and Policies for Informatics' (SPIN) was held in Torremolinos. It was attended by some 80 nations, most of them from the developing world, and here the close relationship between computing and development was explored in depth.

In the original United Nations study four categories of computer development were identified. The first, which was called the Initial level, really covered those countries which had no effective computing capability of their own. Today such countries as Ethiopia, Lesotho and the Solomon Islands would come into this category.

The second, called the Basic level, is attained by countries which have clearly started upon the computer development road. They will have some significant use of computers in government and there will be education and training programmes in computer technology. This category would include such countries as Kenya, Nigeria, Egypt, Indonesia, Venezuela and Chile.

The third or Operational level defines the situation where computing is well established within the national environment. There will be a well identified education programme; major use of computing in government; design and production of software and maybe some hardware. Examples here are India, Singapore, Korea, Mexico and Brazil.

The fourth or Advanced level refers to those nations which are virtually capable of supporting themselves in computing terms, with fully matured design and production, professional and educational capabilities.
This category would include the UK, the USA, Japan, Australia and a number of European countries.

The rate of computing development in the most industrialised nations is very advanced indeed, and we have come a long way in a mere 30 years since the early days of computing. The pace of development is still accelerating and the gap between the most advanced and the least advanced nations is widening. This gap can be analysed in a number of areas:

\section{The systems gap}

Successful implementation of computer systems is dependent upon there being a systems infrastructure on which to build. It is easy in advanced countries such as the UK to take this infrastructure for granted: For example, our taxation system works comparatively efficiently because it has built up over the years and because individuals, companies, banks, accountants and so on are accustomed to the procedures. Where these procedures do not exist or are inefficient, it becomes difficult if not impossible to devise a computer based system to meet the national requirement.

There is often resistance against the establishment of interdependent systems within a country which will take a very long time to be broken down at the existing pace of social change. Only by concerted national effort, sponsored by government, can the pace of change be accelerated to allow the benefits of systemisation to be attained.

\section{The education gap}

This is certainly the principal barrier to successful development and is at the root of the problems which developing countries face. For a country to move from the Basic to the Operational level of development implies an education programme on a national scale.

This means:

- a level of general education which will prepare the population to participate in a computer based culture. Sooner or later, directly or indirectly, all citizens will be in contact with the spreading 
implementation of computer technology and will be intimately involved and affected by its applications;

- a level of general education which will provide a pool of trained minds sufficiently large to form a source of computer practitioners;

- a level of higher education which will mature the nation's computer scientists, computer professionals, and teachers;

- a level of management education which creates business, commercial and government environments where computer methods can be introduced;

- and finally, a level of technical education and training which can produce the systems analysts, programmers, operators and engineers who are necessary to develop, maintain and support the growth of applications.

\section{The technology gap}

It seems likely that the technology gap can never be bridged. The cost of setting out on a technological development path and catching up with the world leaders would be outside the capability of practically any nation. This does not mean that a country should not attempt to carve out a particular area of technological leadership, but there must in future always be some dependence upon the most advanced nations.

One major area where the developing countries may aspire to equality is in software technology. Certainly, the development of an indigenous capability in this area can be achieved far more quickly and far more cheaply than for hardware.

\section{The application gap}

What are the applications which developing countries see as having priority? Certainly there is some common ground with the advanced countries, particularly in private industry and in government administration where the problems and the achievable benefits are of a similar nature. They are not the same, however, and this has implications for the transferability of software. Indeed the differences dictate the need for the development of indigenous software competence.

Almost certainly, it is in the public sphere that the real differences of priority exist between developed and developing countries and where they will be manifested. Examples of the sorts of activities which could be pursued are development and exploitation of natural resources. Many developing countries have immense resources available to them. They have an enormous task to turn the benefits from those resources into economic and social growth for the country as a whole. Programmes of work to achieve this require major support in planning, in project management and control and in scientific research and analysis. The resulting operational systems require continuing management. All these activities imply requirements for computer systems.

Raising educational standards. Many developing countries will have half their population under the age of 15 during the $1980 \mathrm{~s}$. Automated learning systems are needed to cope with the educational task.

Health care. Computers have already enabled major advances in raising the standard of health care for epidemiology and administration systems through the work of the World Health Organisation. There is further potential in this area.

Increasing food production. Raising output is a matter of improved agricultural methods, development of specialised strains, improved distribution and, above all, national planning. How do the developing countries see the priority here?

\section{The power gap}

As information systems develop and increasingly lie within the control of the most developed countries, particularly the USA, the developing nations are becoming increasingly concerned that their freedom to manage their own affairs might be eroded. The capacity to process information is fast becoming as valuable an international commodity as oil fuels, and the control of information is a major asset which nations would do well to guard jealously.

An illustration of this problem was quoted at the SPIN conference. The Brazilian representative reported that a factory in Brazil owned by a United States multinational has its production control system linked by satellite back to the parent company in the USA. In theory the parent company was in a position simply to turn the factory off if it so wished.

The United Nations report came to four conclusions about the role of computing in developing countries. These were:

i) 'Computer technology will increase in importance in the developing countries and its diffusion and sound application can make a significant contribution in accelerating the rate of their economic and social development'.

ii) 'Education and training for the application of computers to accelerate the process of economic and social development must receive first priority'. Thus, whilst the careful and judicious application of computers can speed up the process of national development, this can only happen if there is effective education and training first. 
iii) 'Each developing country needs a broad national policy consistent with its national goals on the application of computer technology'. Obviously plans will look very different in different countries and they will depend on the current state of development, the general level of education, the higher education programme, the financial, industrial and human resources available, the status of the communications systems and the pressures of immediate priorities.

iv) 'International cooperation needs to be increased in activities relating to the application of computer technology to development'. The developing countries need help of all kinds to enable them to take advantage of world-wide computing development. It is up to the developed nations to provide support.

\section{The United Kingdom as a source of technical assistance}

It is clear that the UK has the experience and skills necessary to help the developing countries move into the information technology age. It has a mature infrastructure in computing which has developed over the last 30 years. It is possibly as advanced technically as any other country, and in some areas it leads the world. It has an educational system second to none, which at university level is nationally planned and coordinated and whose quality extends in depth to secondary level. It has a developed government machine for planning the use and development of computing in central government. It covers the full range of industry competence: hardware, software and services. The UK is also a major contributor to the establishment of international standards. The extent of user application is fairly comprehensive and sophisticated. The work of the National Computing Centre is known and highly respected throughout the UK and overseas, and the British Computer Society is one of the leading professional bodies in the world.

Whilst initiatives are taken from time to time, of ten in response to outside requests, for the UK to help and advise other countries in this area we do seem to have a marked inability to coordinate our resources. An example of the problem may be illustrated by referring to the visit of a UK delegation to Mexico City in 1978. The purpose of the visit was to hold a seminar on computing in the public sector for an audience of Mexican government technical and administration officials. The delegation was lead by HMG and included representatives of the UK services industry under the aegis of the Computing Services Association, ICL (the largest UK computer firm), the National Computing Council (NCC) and the British Computing Society (BCS). The intention was that we should impart useful and valuable information to the Mexican authorities and that this would be the beginning of a process of future cooperation. Whilst the conference engendered great interest amongst the delegates at the time, the event failed to achieve the objective of closer cooperation. I believe that the reasons for the failure of this mission were three-fold:

- a shortage of coordination and planning between the parties in preparation for the visit;

- a lack of direction and follow up by the UK Government, bearing in mind that government bodies are not normally empowered to take initiatives in this kind of activity;

- the industry participants believed that their investment in the mission was related to possible short term returns rather than long term investment requiring continuing dialogue and coordinated follow up.

\section{The birth of the UK Council for Computing Development}

The UK Council for Computing Development has been set up as a company limited by guarantee and having charitable status. It is funded by membership subscription and draws its expertise primarily from its members. Since the announcement of the formation of the Council in May 1981 most effort has been spent in seeking support from individuals and organisations for the proposal. As at the end of October 1981 some 70 individuals and 30 organisations have joined, providing both financial and technical viability. These organisations include a number of companies in the computing industry, users such as British Telecom and the Central Computer and Telecommunications Agency, universities and poly technics and institutions such as the BCS, the NCC and the British Council. The Council is now operational and its immediate plans are to launch a major effort to publicise itself in the developing countries and the International Agencies, and to offer its services to those in need.

The Council will operate in two principle modes in its dealings with developing countries. It will tend to deal, in the first instance at any rate, with governmental or official bodies, and its main aim will be to establish a bilateral agreement with specific countries that the UK will help them in formulating a national computing policy and the computing development strategy that would arise from this. This in turn would lead to specific tasks such as the establishment of a national training institute, the formation of a national computing centre, setting up professional and technical standards, encouragement of an indigenous computing industry, curriculm development in education and maybe application work in areas of strategic importance to a country. In supporting these activities the Council will have a part to play in seeking funds from the appropriate 
development agencies with which it will have links of its own.

In addition to this major responsibility in respect of specific countries we may expect many requests from other countries for ad hoc support for particular tasks. The Council will respond to these as far as it is able within the limits of its resources.

\section{Conclusion}

The objectives of UKCCD should be seen in the context of policies in general. In the first place the aim is to help the poorer countries to help themselves, rather than to attempt to pour resources into the task of doing the job for them. In the second place the benefit should be mutual in the sense that the contributors will themselves gain in the long term from their contribution and participation. Whilst it is clear that industry participation is not going to result in the development of rapid business, most of the industry members see long term benefits to themselves in helping these countries to improve their effective and efficient use of computing, and to establish links which can be developed in the course of time. 